\title{
FERTILITY-SPARING HYSTEROTOMY IN MALIGNANT TROPHOBLASTIC TUMOURS TREATMENT
}

\author{
Nataliya Tsip \\ Department of Oncogynaecology \\ National Cancer Institute \\ 33/43 Lomonosova str., Kyiv, Ukraine, 03022 \\ tsipnataly@gmail.com
}

\section{Abstract}

The aim is to improve treatment efficacy and life quality of patients with malignant trophoblastic tumours.

Fertility-sparing hysterotomy with uterine reconstruction was carried in 16 patients aged of 17 to 32 years: 2 cases due to urgent and 13 - due to planned indications.

On the basis of research, the indications for the urgent and planned fertility-sparing hysterotomy with uterine reconstruction in patients with malignant trophoblastic tumours were formulated. No postoperative complications. Steady remission in all cases. Follow up from 1 to 17 years (averaged 9.2 years).

1. Localized uterine resection with uterine reconstruction - the method of choice in malignant trophoblastic tumours surgical treatment.

2. Fertility-sparing hysterotomy with uterine reconstruction is only possible in centers which are experienced in the complex multimodality treatment of gestational trophoblastic neoplasms.

3. Basic requirement of fertility-sparing surgery is beginning adjuvant chemotherapy as soon as possible.

Keywords: malignant trophoblastic tumours, chemoresistance, fertility-sparing surgery.

\section{Introduction}

Gestational trophoblastic disease (GTD) comprises a spectrum of pregnancy associated disorders from the pre-malignant conditions such as complete and partial hydatidiform moles (HM) through to the malignant choriocarcinoma (CC) and very rare placental site trophoblastic tumour/epithelioid trophoblastic tumour (PSTT/ETT) [1]. The malignant forms of the disease are also known as gestational trophoblastic tumours or neoplasia (GTN).

Chemotherapy (CT) is the main treatment option in the most cases. Despite the fact that the treatment with chemotherapy (CT) has been one of the success stories of modern-day chemotherapy, surgery is still important for GTN patients. Surgical procedures can be divided into the following groups:

1. Urgent surgical procedures:

- gynaecological surgeries;

- nongynaecological surgeries.

2. Planned surgical procedures:

- hysterectomy (with/without adnexa);

- fertility-sparing hysterotomy with uterine reconstruction;

- excision of chemo-resistant metastasis.

3. Low-invasive techniques.

Most women with GTN are of reproductive age. For this reason, fertility becomes an important issue. Life-threatening haemorrhage can occur in women with GTN, as the uterus is usually enlarged with vascular and friable tumour inside. Traditionally, hysterectomy has been the main solution to this urgent disastrous condition [2]. Selective angiography and transcatheter embolisation of uterine artery by gelfoamparticles is now becoming popular in intractable uterine bleeding [3, 4]. This technique is an attractive alternative to hysterectomy because it is minimally invasive and has a potential to preserve fertility [5,6]. Successful term pregnancies have been reported after uterine artery embolisation in GTN. For instance, selective uterine artery embolization in 31-year-old woman with heavy bleeding was described by Garner E. I. et. al. [7]. After two first-trimester spontaneous abortions, the patient successfully completed a normal pregnancy [7]. 
$13.9 \%$ of pregnancies in a larger group (15 women) ended in miscarriage too [8]. However, small numbers of reported cases make it difficult to make definitive statements about obstetric outcomes.

Uterine resection, primary closure and balloon tamponade have also been reported for the control of bleeding in GTN $[9,10]$. These, however, are limited in selected cases only, and more reports are needed to establish their role.

Hysterectomy may be required for the management of excessive uterine bleeding either at presentation or after the onset of chemotherapy and in the management of chemoresistant disease localized in pelvis [11]. For refractory diseases with single focus in the uterus hysterectomy is traditionally carried out $[12,13]$. According to Clark R. M. et. al. [13], complete remission was achieved in $75,8 \%$ patients who underwent hysterectomy to treat chemotherapy-resistant GTN.

The issue concerning the uterus organ-preserving surgeries has been little studied up to now, especially in metastatic GTN [14]. Indications, contra-indications and complications after such surgeries are not described in the literature.

\section{Aim of research}

To improve treatment efficacy and life quality of patients with malignant trophoblastic tumours.

\section{Materials and methods}

Fertility-sparing hysterotomy with uterine reconstruction was carried in 16 patients aged of 17 to 32 years (Table $\mathbf{1}$ ).

Table 1

General characteristics of patients

\begin{tabular}{|c|c|c|c|}
\hline & Urgent surgeries & Planned surgeries & Total \\
\hline Patients' number & 2 & 13 & 15 \\
\hline Age (average) & $21,31(26)$ & $17-32(25)$ & $17-32(25)$ \\
\hline Prognostic score (FIGO) & 2 & 9 & 8 \\
\hline Latent period (month) & 4,5 & 7,4 & 6,8 \\
\hline Postoperative complications & 0 & 0 & 0 \\
\hline Steady remission & 2 & 13 & 15 \\
\hline Mortality & 0 & 0 & 0 \\
\hline Follow-up (years) & $17 ; 6$ & $1-12(6,3)$ & 9,2 \\
\hline
\end{tabular}

In $50 \%$ of patients the pregnancy, initiating the development of GTN, was the first one. The latent period varied from 1 to 15 months and averaged at 6,8 months. In most patients (73,3\%) of study group the malignant trophoblastic tumour were initiated by HM. According to the data of radiological methods tumour nodes from 3 to $4 \mathrm{~cm}$ in diameter were found in myometrium in all patients. Ovarian cysts with dimensions more than $6 \mathrm{~cm}$ in diameter were diagnosed in 2 women (13,3\%). I stage was diagnosed in 9 women (60\%), II stage - in $1(6,7 \%)$, III stage - in $5(33,3 \%)$. Initially low risk disease ( $\leq 6$ score) group was in $7(46,7 \%)$ women; high-risk $(\geq 7$ score $)-$ in $8(53,3 \%)$ women.

Antitumor treatment of low risk group patients was single-agent chemotherapy with methotrexate (MTX) according to the standard national protocol $\left(50 \mathrm{mg} / \mathrm{m}^{2}\right.$ intravenous weekly). For high-risk or chemoresistant patients - multiagent chemotherapy (EMA-CO, EMA-EP, BEP or TP). 
Urgent hysterotomy was performed in two women (not previously received special treatment). Planned surgical procedures in our research were carried out in 11 patients with chemotherapyresistant tumours and in 2 women with relapse of disease (the patients got the primary treatment at regional hospitals). Restaging in patients with recurrent disease was conducted.

The level of human chorionic gonadotrophin (hCG) in serum was determined using a sandwich assay - version ELISA.

Stain in histopathology was performed using haematoxylin and eosin.

All cytometric analysis were performed on the device FACScan (Becton Dickinson), equipped with an argon laser with a wavelength of $488 \mathrm{~nm}$. To obtain and analyze data CellQuest software for Mac was used. Fluorescence Measurements were made by narrowband filter 585/42 nm.

\section{Results}

Urgent hysterotomy was performed on two women with GTN aged 21 and 31 year. Obstetric anamnesis and clinical characteristics of patients are presented in Table 2.

Table 2

Clinical characteristics of patients undergoing urgent hysterotomy

\begin{tabular}{cccccccc}
\hline $\begin{array}{c}\text { No. } \\
\text { Ser/No }\end{array}$ & $\begin{array}{c}\text { Age, } \\
\text { years }\end{array}$ & Gravidity & $\begin{array}{c}\text { Antecedent } \\
\text { pregnancy }\end{array}$ & $\begin{array}{c}\text { Size of tumour } \\
\text { node, } \mathbf{c m}\end{array}$ & Type of operation & $\begin{array}{c}\text { Morphology of } \\
\text { tumour node }\end{array}$ & $\begin{array}{c}\text { Postoperative } \\
\text { courses of } \\
\text { chemotherapy }\end{array}$ \\
\hline 1 & 21 & 1 & Abortion & 3 & $\begin{array}{c}\text { Resection of uterine fundus } \\
\text { with tumour node }\end{array}$ & CC & 6 \\
2 & 31 & 3 & HM & 3 & $\begin{array}{c}\text { Hysterotomy with an exci- } \\
\text { sion of tumour node in the } \\
\text { cornual region of the uterus }\end{array}$ & CC & 7 \\
\hline
\end{tabular}

The indications for urgent surgical procedures in these patients were:

a) In the first case - intra-abdominal bleeding as a result of penetration of the uterus by a tumour in the 21 year old woman, (D0A1) - a resection of uterine fundus with tumour node was fulfilled;

b) In the second case - intra-abdominal bleeding in a 32 years woman (D2A0). In this case hysterotomy with an excision of tumour node in the cornual region of the uterus was done.

In both cases tumoral tissue invaded the whole thickness of the uterus, from endometrium to serosa. In the first case the tumour node, developed 3 months after abortion morphologically was choriocarcinoma (CC). In the postoperative period 6 cycles of single-agent chemotherapy with MTX were held (the first cycle of chemotherapy was held in a 5th day of postoperative period).

In the second case - the malignant GTN developed 6 months after complete HM evacuation. In a postoperative period 7 cycles of single-agent chemotherapy with MTX were held (the first cycle - in a $7^{\mathrm{s}}$ day).

Planned surgical procedures in our research were carried out in 11 patients with chemotherapy-resistant tumours and in 2 women with relapse of disease (the patients got the primary treatment at regional hospitals). Clinical characteristics of patients undergoing planned hysterotomy are presented in Table 3.

According to the data of radiological methods (ultrasound with Colour Doppler and MRI) the tumour nodes in these patients had irregular shape, heterogeneous structure and sharp outlines. Color loci predominantly were along the contour of the tumor node. The spectrogram of blood flow in the tumor node characterised by low resistance and peripheral resistance: PSV - 11,4 cm/s; RI - 0,34; PI - 0,42 (Fig. 1).

The spectrogram of blood flow in the uterine artery characterised by increased maximum systolic speed and low resistance index: PSV - 56,7 cm/s; RI - 0,52; PI - 1,22 (Fig. 2). 
Table 3

Clinical characteristics of patients undergoing planned hysterotomy

\begin{tabular}{|c|c|c|c|c|c|c|c|}
\hline $\begin{array}{l}\text { No. } \\
\text { Ser/No }\end{array}$ & $\begin{array}{l}\text { Age, } \\
\text { years }\end{array}$ & Gravidity & $\begin{array}{l}\text { Antecedent } \\
\text { Pregnancy }\end{array}$ & $\begin{array}{l}\text { Prognostic score } \\
\text { (FIGO) }\end{array}$ & $\begin{array}{c}\text { Preoperative } \\
\text { courses of } \\
\text { chemo-therapy }\end{array}$ & Operation type & $\begin{array}{l}\text { Size of tumour } \\
\quad \text { node, } \mathrm{cm}\end{array}$ \\
\hline 1 & 27 & 1 & Term & 6 & 4 & Hysterotomy & 3,0 \\
\hline 2 & 27 & 1 & $\mathrm{HM}$ & 8 & 4 & $\begin{array}{c}\text { Hysterotomy }+ \\
\text { Thoracotomy+ } \\
\text { resection of } \\
\text { the bladder }\end{array}$ & 4,0 \\
\hline 3 & 28 & 2 & Abortion & 7 & 18 & Hysterotomy & 3,0 \\
\hline 4 & 25 & 1 & Abortion & 9 & 5 & Hysterotomy & 3,0 \\
\hline 5 & 32 & 5 & $\mathrm{HM}$ & 5 & 7 & Hysterotomy & 3,0 \\
\hline 6 & 17 & 1 & $\mathrm{HM}$ & 6 & 11 & Hysterotomy & 2 nodes (each 2,5) \\
\hline 7 & 23 & 1 & $\mathrm{HM}$ & 6 & 8 & Hysterotomy & 2,5 \\
\hline 8 & 22 & 1 & $\mathrm{HM}$ & 11 & 4 & Hysterotomy & 3,0 \\
\hline 9 & 25 & 1 & $\mathrm{HM}$ & 7 & 7 & Hysterotomy & 2,5 \\
\hline 10 & 26 & 1 & $\mathrm{HM}$ & 9 & 7 & Hysterotomy & 3,0 \\
\hline 11 & 24 & 1 & $\mathrm{HM}$ & 10 & 9 & Hysterotomy & 3,0 \\
\hline 12 & 27 & 1 & $\mathrm{HM}$ & 8 & 7 & Hysterotomy & 4,0 \\
\hline 13 & 25 & 1 & $\mathrm{HM}$ & 9 & 6 & Hysterotomy & 3,5 \\
\hline
\end{tabular}

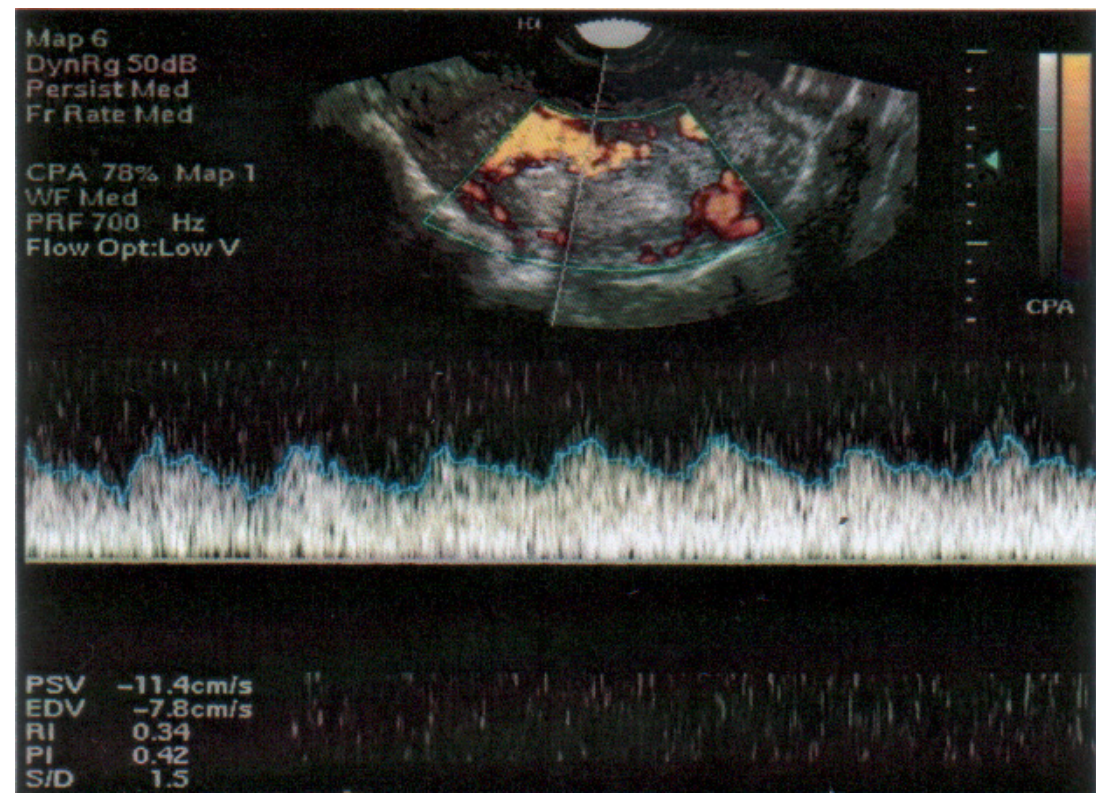

Fig. 1. The spectrogram of blood flow in the tumor node 


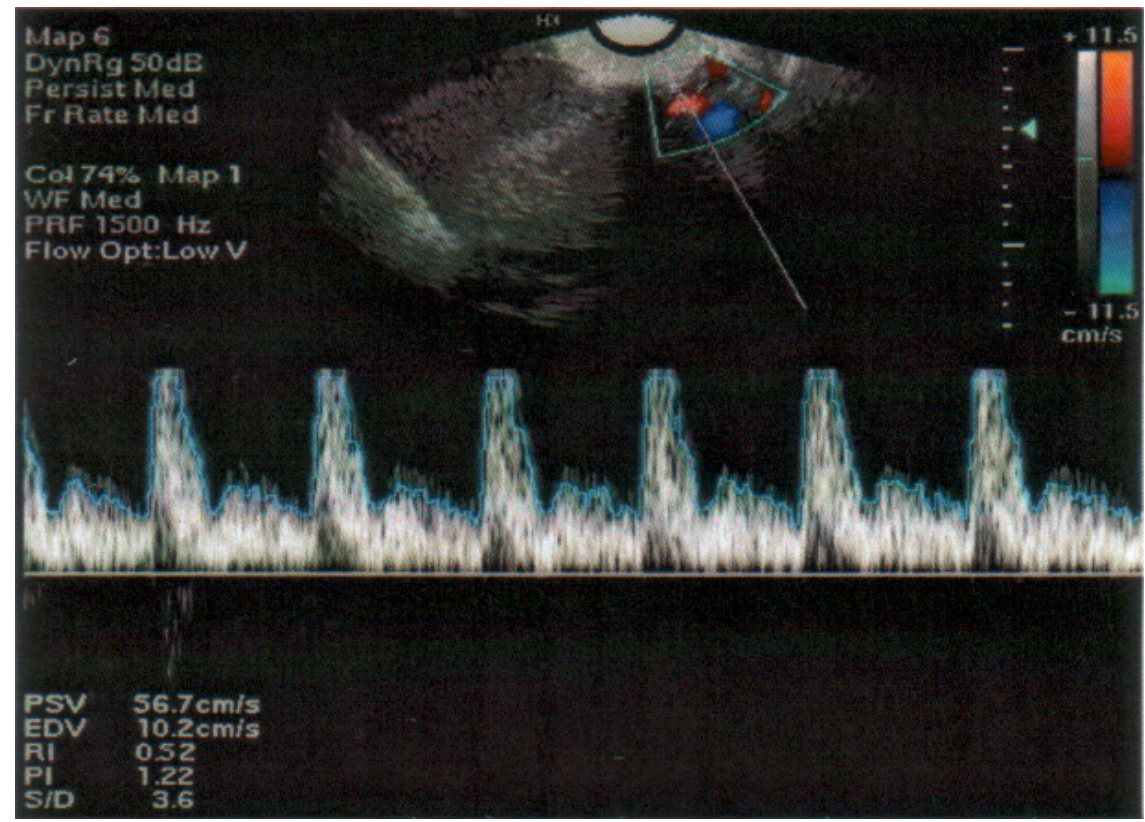

Fig. 2. The spectrogram of blood flow in the uterine artery

Phases of the operation were similar for all patients of study group.

I. Removal of the tumor node, temporary shutdown of the uterine blood flow

After laparotomy and revision of the pelvis and abdominal cavity on the ascending branches of uterine vessels on the right and left side of the uterus were imposed atraumatic clamps, temporarily muted the uterus from the circulation. The aim of this phase - to reduce intraoperative blood loss and prevent the dissemination of tumor cells.

During the removal of the tumor nodes were used rational cuts, taking into account the topography of blood vessels, muscles and nerves of the uterus. Tumor nodes are removed only by a sharp, indented from the edge of tumors $0.5-1.0 \mathrm{~cm}$, carried out extra careful hemostasis.

II. Restoration of the uterine wall

The uterus was repaired in three layers with delayed-absorbable suture. After the main phase of the operation performed for 10 to 15 minutes, clamps are removed.

III. Re-checked hemostasis

Re-checked hemostasis after restoration of blood circulation in the uterus was done. If necessary have been imposed additional seams on the uterus (Fig. 3).

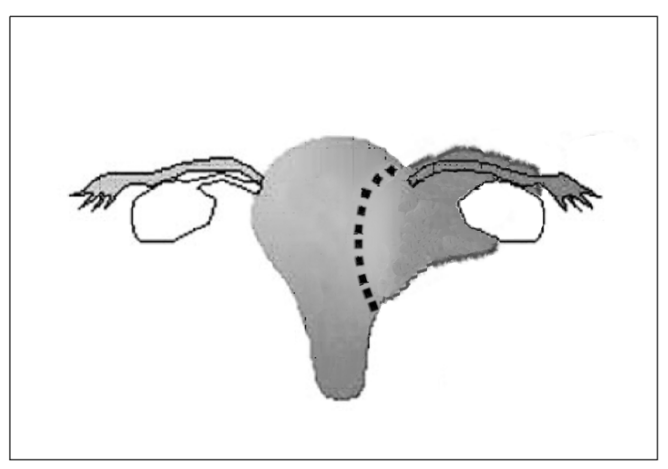

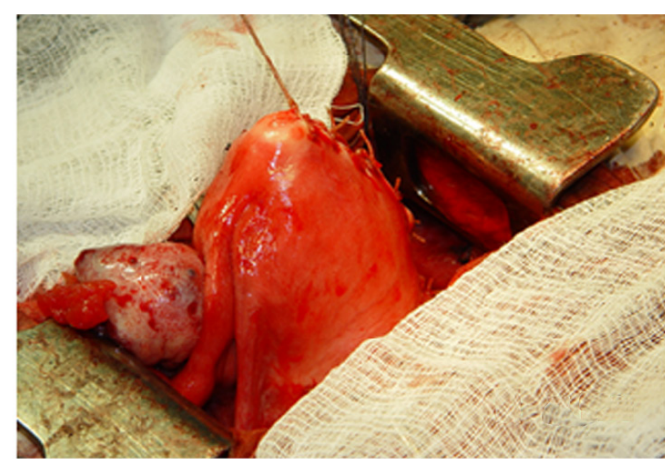

$b$

Fig. 3. Hysterotomy with uterine reconstruction in patient with chemo-resistant trophoblastic tumour: $a$-scheme of the operation; $b$ - uterus after reconstruction 
The basic condition of fertility-sparing hysterotomy with uterine reconstruction in patients with malignant trophoblastic tumours - minimal palpation of tumour node to reduce the risk of tumour cells dissemination. If the lesion could not be seen, intraoperative ultrasound should be used.

There was no postoperative complication. Steady remission was observed in all cases. Follow-up period was 17 and 6 years after urgent and 1-12 years (on average 6.3 years) after planned surgery.

In 3 patients with chemotherapy - resistant GTN were multiple metastases to the lungs. So two of them were treated by adjuvant multiagent chemotherapy according to the protocol TP, one patient - by one cycles multiagent chemotherapy according to the protocol BEP (from further treatment patient refused). Steady remission in all cases. Follow- up varied from 5 to 7 years (on averaged 5.4 year).

\section{Discussion}

The issue concerning the uterus organ-preserving surgeries in malignant trophoblastic tumors treatment has been little studied up to now.

There are few publications, describing urgent localized uterine resection, followed by uterine reconstruction $[6,14-18]$. The limited number of clinical observations is apparently caused by the fact that such treatment option was considered as wrong earlier. But now we know that fertility-sparing hysterotomy with excision of the tumour node (instead of hysterectomy) in an urgent way is possible even in the patients with a PSTT [15]. Physicians should therefore be aware of possible treatment alternatives to preserve fertility.

On the basis of the analysis of our own experience and the data of literature we have formulated the following indications for the urgent fertility-sparing hysterotomy with uterine reconstruction in patients with malignant trophoblastic tumours:

- solitary tumour node in myometrium (according to the data of radiological methods);

- absence of children in the family or strong desire to preserve fertility;

- young age of the patient.

Basic requirement of fertility-sparing treatment program is the beginning of chemotherapy in the early postoperative period.

Positive clinical practice of urgent hysterotomy in patients with malignant trophoblastic tumours became a basis for the substantiation of possibility of analogous treatment option in patients with chemo-resistant and relapsed disease.

In determining the chemotherapy-resistant disease, we were guided by the same criteria that are formulated by F. Feng and Y. Xiang [19].

Definition of chemotherapy-resistant GTN and high-risk factors of drug resistance were:

- plateau (less than for $50 \%$ ) of hCG level decrease;

- increase of hCG level (three consecutive measurements);

- development of new metastases despite treatment;

high-risk factors of drug resistance:

- spread disease (metastatic site other than lung or vagina);

- the number of metastatic organs;

- the size of metastatic lesion being more than $3 \mathrm{~cm}$ in diameter;

- prior unsuccessful chemotherapy;

- duration of disease greater than 4 month.

- According to the data, received out earlier in our institute [20], exists a positive correlation relationship between the level of hCG and the sizes of trophoblastic node in myometrium. In patients with chemotherapy-sensitive tumors, this correlation coefficient was $r=0,88+0,09(p<0,05)$ (Fig. 4).

In patients with chemotherapy-resistant tumors, this correlation coefficient was $r=0,79 \pm 0,14$ $(\mathrm{p}<0,05)$ (Fig. 5).

The necessity for chemotherapy after urgent operations is not in doubt. In patients with recurrent and chemotherapy-resistant disease levels of hCG normalized after tumor removal. Does adjuvant chemotherapy indicated for these patients? How many cycles? Clear answers to these questions are currently unavailable. 


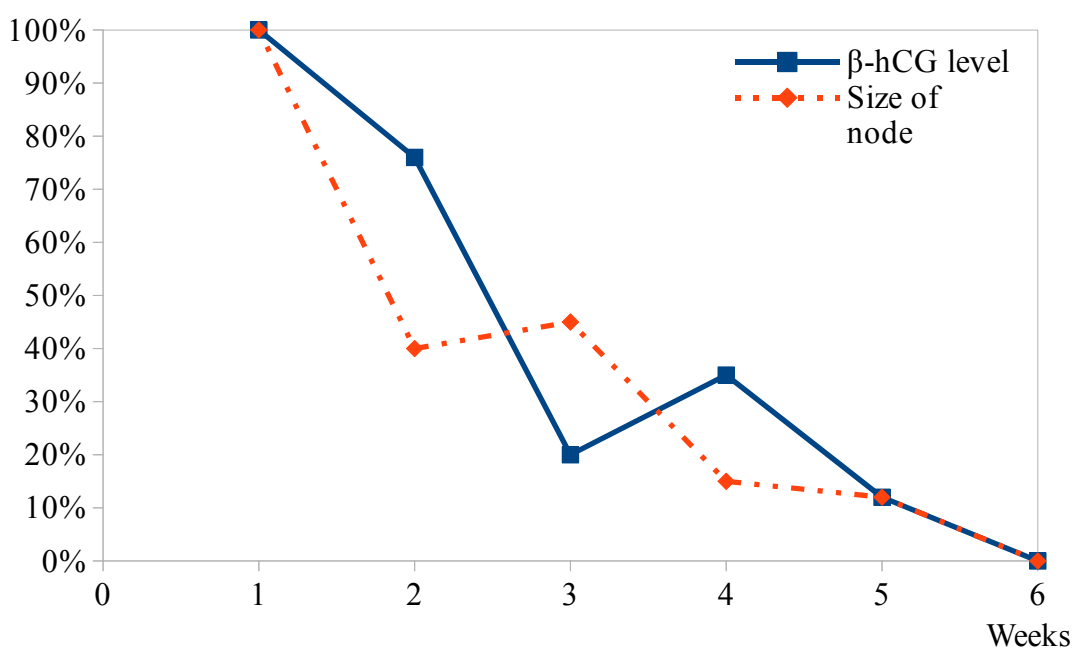

Fig. 4. Relative changes in the hCG level and the size of chemosensitive trophoblastic tumor in myometrium

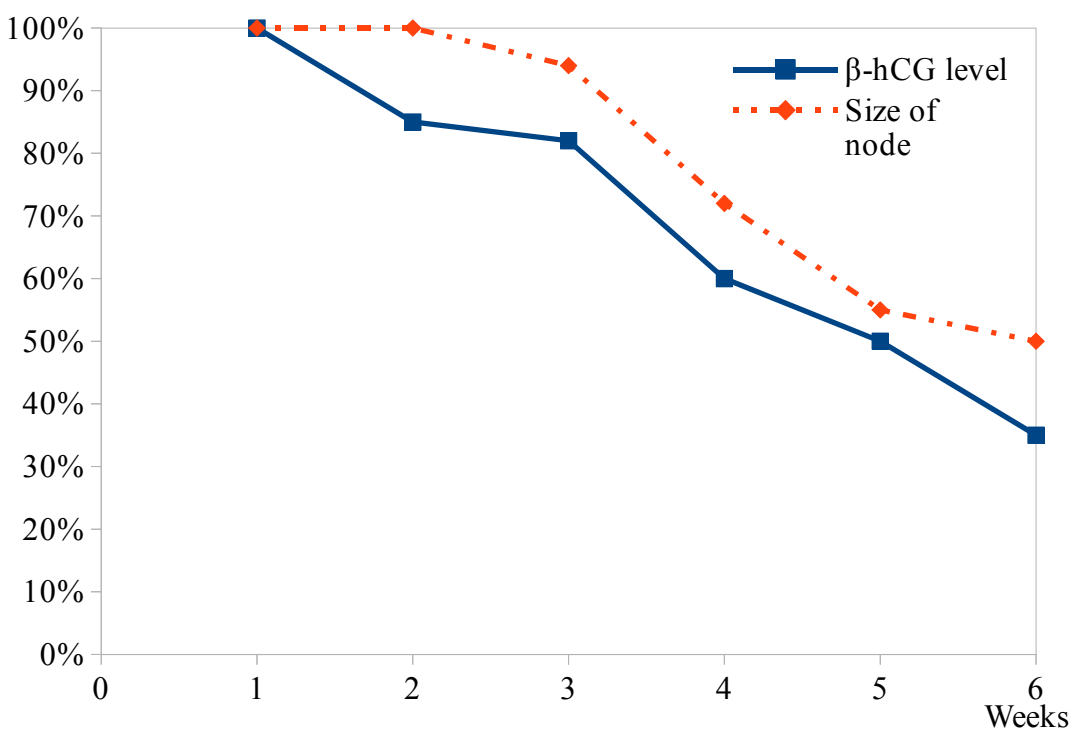

Fig. 5. Relative changes in the hCG level and the size of chemoresistant trophoblastic tumor in myometrium

What should be the treatment strategy for patients with chemoresistant trophoblastic tumors after planned surgery?

According to our previous data - the tumor tissue in myometrium is in necrosis in all cases. The volume of viable tumor tissue is only $2 \%$ (Fig. 6).

However, according to the flow cytometry, the level of apoptosis was only $75 \%$. It was not possible to distinguish cells in apoptosis and necrotic cells by measurement of their DNA content by flow cytometry. But it was found that the remaining $25 \%$ of tumor cells contain diploid amount of DNA with accessible S-phase fraction which was $14 \%$.

Therefore, in the tumor remain cells with pathologic proliferative activity. Consequently, after the planned fertility-sparing hysterotomy with uterine reconstruction in patients with malignant trophoblastic tumours adjuvant chemotherapy is mandatory until 8 weeks normal hCG levels.

After fertility-sparing hysterotomy with uterine reconstruction, myometrial structure in the projection of scar is inhomogeneous during 6 month. 3 month after operation angioarchitectonics of uterus is preserved. 

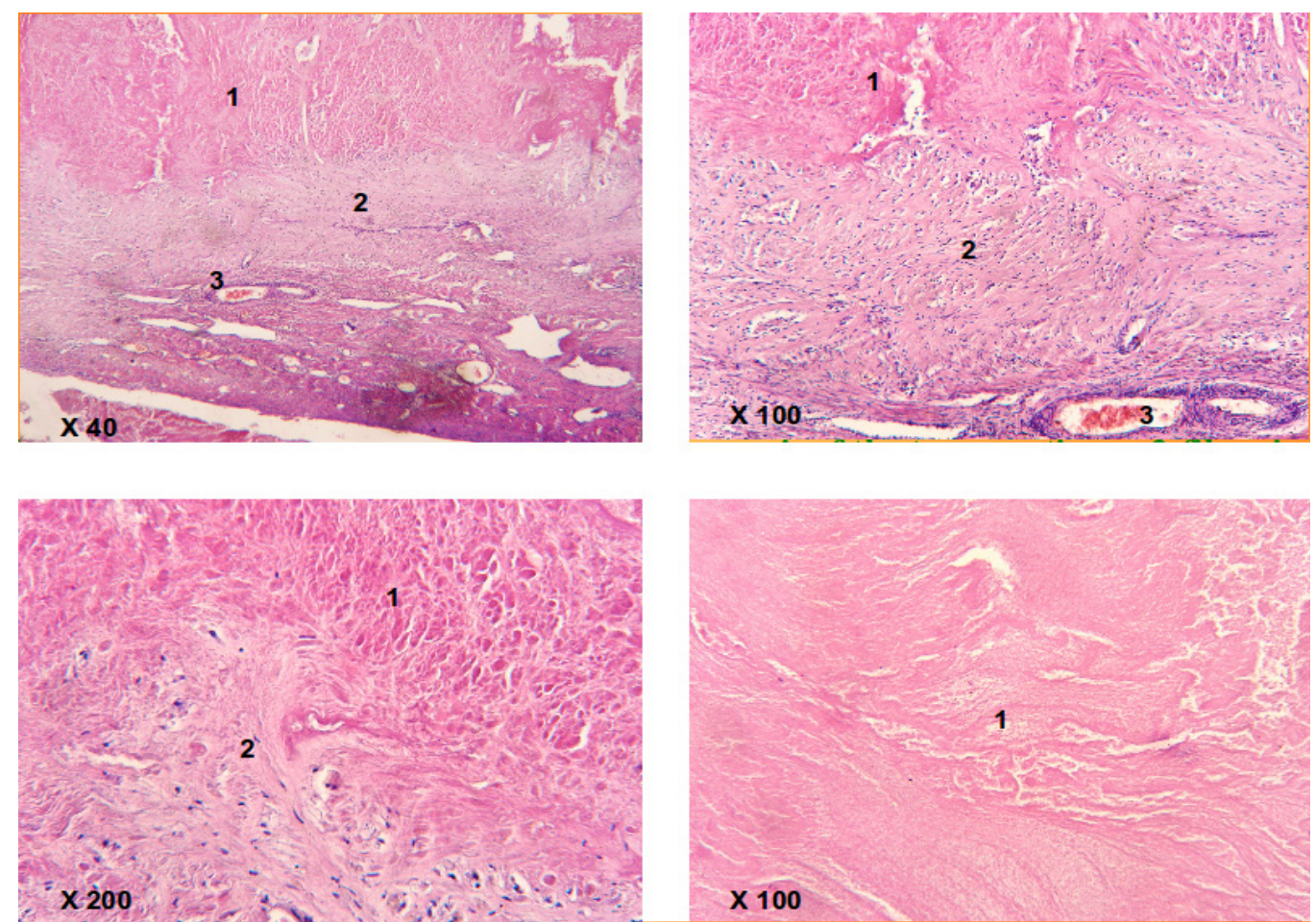

Fig. 6. Chemo-resistant trophoblastic tumor; operation material after uterine resection: 1 - necrosis; 2 - fibrosis; 3 - hyalinosis of tumour tissue

Thus, fertility-sparing surgical treatment of patients with recurrent and chemotherapyresistant postmolar GTN is possible even in metastatic disease.

Some researchers have reported on the peculiarities of surgical treatment, taken at their Trophoblastic centers. In Peking Union Medical College Hospital methotrexate was injected within the myometrium adjacent to surgical margins to minimize the possibility of inducing metastases [21]. Vasopressin was used to minimize bleeding and an argon-beam coagulator was used to evaporate the myometrium adjacent to the tumour without damaging the uterus in some centers [21]. We consider that adequate indentation from the edge of the tumor $(0.5-1.0 \mathrm{~cm})$ and extra careful hemostasis in planned fertility-sparing surgery are enough.

On the basis of the analysis of our own experience and the data of literature we have formulated the following indications for the planned fertility-sparing hysterotomy with uterine reconstruction in patients with chemotherapy-resistant GTN:

- absence of children in the family, strong desire to preserve fertility;

- young age of the patient;

- tumour node $<4 \mathrm{~cm}$ or two adjacent tumour nodes (the same total size);

- serum hCG as low as possible.

Pregnancy in these patients is a high risk owing to possible uterine rupture caused by uterine scars [22], therefore these patients should be monitored closely in pregnancy by ultrasound assessment of uterine thickness.

\section{Conclusion}

1. Localized uterine resection with uterine reconstruction - the method of choice in malignant trophoblastic tumours surgical treatment.

2. Fertility-sparing hysterotomy with uterine reconstruction is possible only in centers which are experienced in the complex multimodality treatment of GTN.

3. Basic requirement of fertility-sparing surgery is beginning adjuvant chemotherapy as soon as possible. 


\section{References}

[1] Seckl, M. J., Sebire, N. J., Fisher, R. A., Golfier, F., Massuger, L., Sessa, C. (2013). Gestational trophoblastic disease: ESMO Clinical Practice Guidelines for diagnosis, treatment and follow-up. Annals of Oncology, 24, 39-50. doi: 10.1093/annonc/mdt345

[2] Tse, K. Y., Ngan, H. Y. S. (2012). Gestational trophoblastic disease. Best Practice \& Research Clinical Obstetrics \& Gynaecology, 26 (3), 357-370. doi: 10.1016/j.bpobgyn.2011.11.009

[3] Moodley, M., Moodley, J. (2003). Transcatheter angiographic embolization for the control of massive pelvic hemorrhage due to gestational trophoblastic disease: A case series and review of the literature. International Journal of Gynecological Cancer, 13 (1), 94-97. doi: 10.1046/j.1525-1438.2003.13016.x

[4] Tse, K. Y., Chan, K. K., Tam, K. F. et. al. (2007). 20-year experience of managing profuse bleeding in gestational trophoblastic disease. The Journal of reproductive medicine, 52, 397-401.

[5] Keepanasseril, A., Suri, V., Prasad, G. R. et. al. (2011). Management of massive hemorrhage in patients with gestational trophoblastic neoplasia by angiographic embolization: a safer alternative. The Journal of reproductive medicine, 56, 235-240.

[6] Tsip, N. P., Vorobyova, L. I. (2008). Surgery in trophoblastic tumors treatment. Practical oncology, 9 (3), 179-185.

[7] Garner, E. I. O., Meyerovitz, M., Goldstein, D. P., Berkowitz, R. S. (2003). Successful Term Pregnancy after Selective Arterial Embolization of Symptomatic Arteriovenous Malformation in the Setting of Gestational Trophoblastic Tumor. Gynecologic Oncology, 88 (1), 69-72. doi: 10.1006/gyno.2002.6861

[8] Tsai, C.-C., Cheng, Y.-F., Changchien, C.-C., Lin, H. (2006). Successful term pregnancy after selective embolization of a large postmolar uterine arteriovenous malformation. International Journal of Gynecological Cancer, 16, 439-441. doi: 10.1111/j.1525-1438.2006.00238.x

[9] Estrella, J. L. D., Soriano-Estrella, A. L. (2009). Conservative Management of Uterine Rupture in Gestational Trophoblastic Neoplasia. International Journal of Gynecological Cancer, 19 (9), 1666-1670. doi: 10.1111/igc.0b013e3181a84252

[10] Kolomeyevskaya, N. V., Tanyi, J. L., Coleman, N. M., Beasley, A. D., Miller, H. J., Anderson, M. L. (2009). Balloon Tamponade of Hemorrhage After Uterine Curettage for Gestational Trophoblastic Disease. Obstetrics \& Gynecology, 113 (2), 557-560. doi: 10.1097/aog.0b013e318193bff3

[11] Doumplis, D., Al-Khatib, K., Sieunarine, K., Lindsay, I., Seckl, M., Bridges, J., Smith, J. (2007). Short communication: A review of the management by hysterectomy of 25 cases of gestational trophoblastic tumours from March 1993 to January 2006. BJOG: An International Journal of Obstetrics \& Gynaecology, 114 (9), 1168-1171. doi: 10.1111/j.1471-0528.2007.01347.x

[12] Alazzam, M., Hancock, B. W., Tidy, J. (2008). Role of hysterectomy in managing persistent gestational trophoblastic disease. The Journal of reproductive medicine, 53 (7), 519-524.

[13] Clark, R. M., Nevadunsky, N. S., Ghosh, S., Goldstein, D. P., Berkowitz, R. S. (2010). The evolving role of hysterectomy in gestational trophoblastic neoplasia at the New England Trophoblastic Disease Center. The Journal of reproductive medicine, 55 (5-6), 194-198.

[14] Milenkovic, V., Jeremic, K., Lazovic, B., Stefanovic, A., Mirkovic, L., Kadija, S. (2011). Fertility sparing therapy for metastatic gestational trophoblastic disease in young patients. International Journal of Gynecology \& Obstetrics, 116 (2), 170-171. doi: 10.1016/j.ijgo.2011.09.020

[15] Lin, H. W., Shieh, C. S., Chen, L. M. et. al. (2001). Spontaneous uterine perforation mimicking ectopic pregnancy as the initial presentation of placental site trophoblastic tumor. Zhonghua Yi Xue Za Zhi, $64,545-550$.

[16] Behtash, N., Ansari, S., Sarvi, F. (2006). Successful pregnancy after localized resection of perforated uterus in choriocarcinoma and a literature review. International Journal of Gynecological Cancer, 16, 445-448. doi: 10.1111/j.1525-1438.2006.00367.x

[17] Leiserowitz, G., Webb, M. (1996). Treatment of placental site trophoblastic tumor with hysterotomy and uterine reconstruction. Obstetrics \& Gynecology, 88 (4), 696-699. doi: 10.1016/0029-7844(96)00124-x

[18] Case, A. M., Wilson, S., Colgan, T. J., Greenblatt, E. M. (2001). Fertility-sparing surgery, with subsequent pregnancy, in persistent gestational trophoblastic neoplasia: Case report. Human Reproduction, 16 (2), 360-364. doi: 10.1093/humrep/16.2.360 
[19] Feng, F., Xiang, Y. (2010). Surgical management of chemotherapy-resistant gestational trophoblastic neoplasia. Expert Review of Anticancer Therapy, 10 (1), 71-80. doi: 10.1586/era.09.169

[20] Kozarenko, T. M., Tsip, N. P., Medvedev, V. E. et. al. (2004). The possibilities of magnetic resonance imaging and color Doppler mapping in monitoring the efficacy of trophoblastic tumor treatment. Women's health, 2 (18), 99-103.

[21] Feng, F., Xiang, Y., Li, L., Wan, X., Yang, X. (2009). Clinical parameters predicting therapeutic response to surgical management in patients with chemotherapy-resistant gestational trophoblastic neoplasia. Gynecologic Oncology, 113 (3), 312-315. doi: 10.1016/j.ygyno.2009.02.025

[22] Lurain, J. R. (2011). Gestational trophoblastic disease II: classification and management of gestational trophoblastic neoplasia. American Journal of Obstetrics and Gynecology, 204 (1), 11-18. doi: 10.1016/ j.ajog.2010.06.072

\title{
DIAGNOSTICS OF CHRONIC OBSTRUCTIVE PULMONARY DISEASE IN REAL CLINICAL PRACTICE: HYPODIAGNISTICS OR HYPERDIAGNOSTICS
}

\author{
Nataliya Cherepii \\ Department of propedeutics of internal medicine \\ Vinnytsia National M. I. Pirogov Memorial Medical University \\ 56 Pyrogov str., Vinnytsia, Ukraine, 21018 \\ nataliya_cherepii@mail.ru \\ Lesia Rasputina \\ Department of propedeutics of internal medicine \\ Vinnytsia National M. I. Pirogov Memorial Medical University \\ 56 Pyrogov str., Vinnytsia, Ukraine, 21018
}

\begin{abstract}
According to the data of the world statistics there is observed the continuous growth of chronic obstructive pulmonary disease (COPD). According to the last data of the World health organization (WHO), for today there is near $250 \mathrm{mln}$ persons with chronic obstructive pulmonary disease (COPD), and this disease becomes as cause of death of near $3 \mathrm{mln}$ persons annually.

Aim: to establish the prevalence of undiagnosed chronic pulmonary disease (COPD) among persons, who consider themselves as healthy ones and regularly undergo medical check-ups; to estimate the frequency of chronic obstructive pulmonary disease (COPD) according to the data of medical documentation.

Methods and materials: 525 persons, older than 35, who did not have in an anamnesis any chronic diseases of respiratory tract, were interrogated. At the following stage, persons, who had taken 18 points or more underwent a spirography with bronchodilatation test, using $400 \mathrm{mcg}$ of salbutamol and were interrogated by the modified questionnaire of short breath by the medical research council (MRC) and test of the chronic obstructive pulmonary disease estimation (COPD) (TEC). There were examined 136 patients, mean age $(51,5 \pm 0,8)$, men were $81(59,5 \%)$ mean age $(52,2 \pm 1,1)$ and women $-55(40,4 \%)$ mean age $(50,7 \pm 0,9)$.

There were analyzed 56 medical stories of patients, treated at therapeutic departments of the city clinic because of internal organs diseases with the concomitant diagnosis of chronic obstructive pulmonary disease (COPD).

Among persons with first revealed chronic obstructive pulmonary disease y 21 (26,6 \%) was reveled I severity degree according to GOLD, in 26 persons (32,9\%) - GOLD II, in $28(35,4 \%)$ - GOLD III, in 4 (5,1 \%) - GOLD IV severity degree, so 32 patients did not receive basic treatment at all.
\end{abstract}

